IOS Press

\title{
Urologic self-management through intermittent self-catheterization among individuals with spina bifida: A journey to self-efficacy and autonomy
}

\author{
Jonathan Castillo ${ }^{\mathrm{a}, *}$, Kathryn K. Ostermaier ${ }^{\mathrm{a}}$, Ellen Fremion ${ }^{\mathrm{b}}$, Talia Collier ${ }^{\mathrm{c}}$, Huirong Zhu ${ }^{\mathrm{d}}$, \\ Gene O. Huang ${ }^{\mathrm{e}}$, Duong $\mathrm{Tu}^{\mathrm{e}}$ and Heidi Castillo ${ }^{\mathrm{a}}$ \\ ${ }^{a}$ Developmental Pediatrics, Department of Pediatrics, Baylor College of Medicine, Houston, TX, USA \\ ${ }^{\mathrm{b}}$ Department of Medicine, Baylor College of Medicine, Houston, TX, USA \\ ${ }^{\mathrm{c}}$ Department of Physical Medicine and Rehabilitation, Baylor College of Medicine, Houston, TX, USA \\ ${ }^{\mathrm{d}}$ Outcomes and Impact Service, Texas Children's Hospital, Houston, TX, USA \\ ${ }^{\mathrm{e}}$ Pediatric Urology, Department of Urology, Baylor College of Medicine, Houston, TX, USA
}

Accepted 31 August 2017

\begin{abstract}
.
PURPOSE: To describe the age of independence in intermittent self-catheterization (ISC) in a diverse patient population and identify factors associated with ISC in individuals with spina bifida.

METHODS: Two hundred patients with myelomeningocele or lipomyelomeningocele, who were $\geqslant 3$ years of age and utilized catheterization for bladder management were included. Data regarding diagnosis, functional level of lesion, race, ethnicity, presence of shunt, method of catheterization, self-management skills, fine motor skills, and cognitive abilities were collected.

RESULTS: Fifty-five percent of individuals were able to perform ISC with a mean age of 9.45 years (SD $=2.97)$ and $22.7 \%$ used a surgically created channel. Higher level of lesion and female gender were associated with a lower rate of ISC. Intellectual disability was present in $15 \%$ of the individuals able to perform ISC and in $40 \%$ of those not able to perform ISC $(p=0.0005)$. Existent self-efficacy regarding activities of daily living (i.e. dressing, bathing, skin care) were associated with ISC $(p<0.0001)$. CONCLUSIONS: The average age of ISC emerged as a target for culturally-appropriate educational interventions to stimulate greater early independence. Future research on factors that may foster an 'independent spirit' early in childhood leading to self-management are warranted.
\end{abstract}

Keywords: Spina bifida, myelomeningocele, neurogenic bladder, self-catheterization, self-management

\section{Introduction}

In the United States, spina bifida (SB), with a birth prevalence of approximately 30 per 100,000 , is the most common non-chromosomal birth defect resulting

${ }^{*}$ Corresponding author: Jonathan Castillo, 8080 North Medical Drive, Suite 180, Houston, TX 77054, USA. Tel.: +1 832822 3400; Fax: +1 832825 3399; E-mail: jcporter@ texaschildrens.org. in a complex genitourinary anomaly [1]. Given recent medical advances, individuals seeking care across our nation for SB related conditions are growing older and are increasingly likely to be adults [2]. Many of these adults have a difficult time reaching full participation in society. Although the reasons for this are multifactorial, it is known that urinary incontinence is associated with a lower health-related quality of life and potentially hinders full participation [3]. Hence, it is clear 


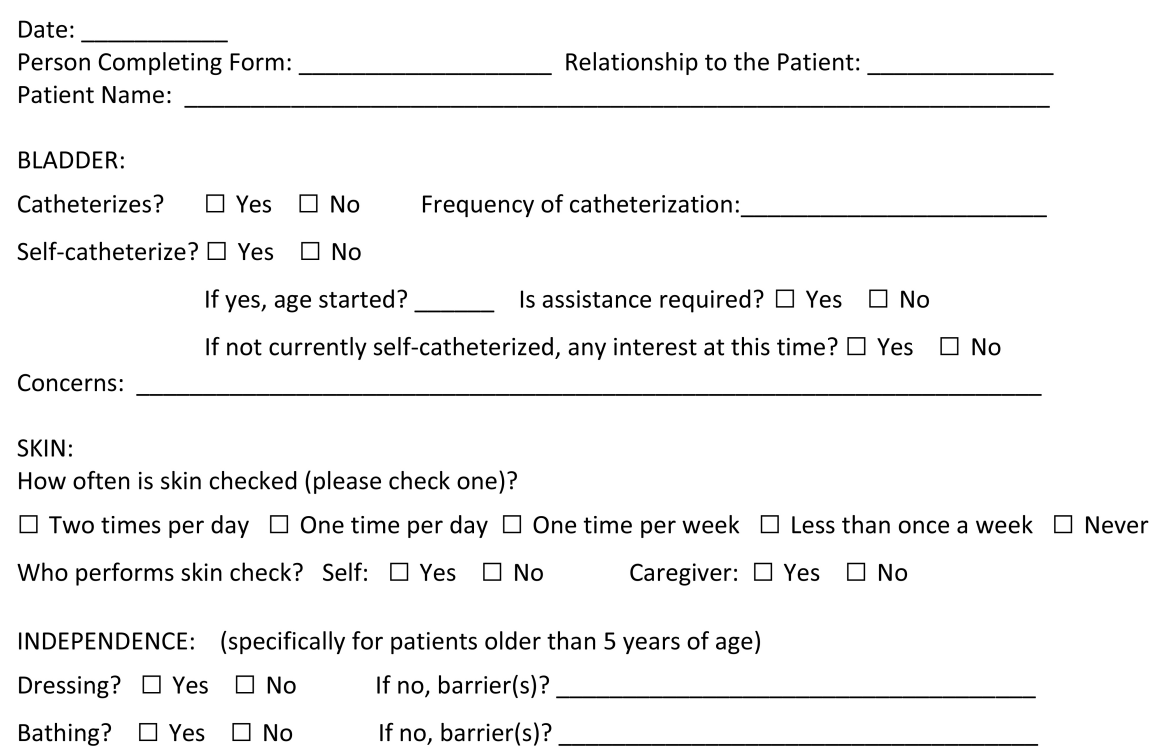

Fig. 1. Spina bifida clinic questionnaire.

that preventive steps must be taken to assure that the growing number of individuals living with SB enjoy the best quality of life possible and transition well into an independent adulthood. Early instruction, therefore, must foster urologic self-management skills.

Clean intermittent catheterization (CIC) has been shown to be of great benefit in the care of SB-related neurogenic bladder and leads to improved long-term outcomes $[4,5]$. Along with improving health-related quality of life, it reduces the frequency of urinary tract infections and preserves renal function [6,7]. Thus, there has been growing interest in promoting timely intermittent self-catheterization (ISC) among patients with neurogenic bladder and on methods to predict patients' ability to practice and master required skills [8, 9]. From improving self-care and independence to subsequent intimacy, this interest in ISC is not unwarranted, as there is a growing body of evidence that ISC has the potential to promote a healthy sense of autonomy and wellbeing [10-12].

In spite of the promising benefits to early implementation of ISC, to date little is known about when children can be expected to be involved in ISC. A few early studies of small cohorts indicated that selfcatheterization can be achieved by five years of age in patients with myelodysplasia $[13,14]$. However, in recent decades, there has been a lack of educational initiatives targeting promotion of self-catheterization at young ages. Moreover, there seems to be a hesitancy in training young children, who may be perceived to have fine-motor and/or cognitive impairments, to be shunted, or to lack an accessible channel, to perform ISC as compared to an earlier era [13]. Therefore, the purpose of this study was to describe the age of independence in ISC in a diverse patient population and to identify factors associated with the use of intermittent self-catheterization in children with spina bifida in an effort to promote early self-management.

\section{Methods}

The study participants were recruited from the Texas Children's Hospital/Baylor College of Medicine multidisciplinary pediatric Spina Bifida Clinic. Beginning in July 2015 through January 2017, 200 patients who were $\geqslant 3$ years of age were enrolled. Only patients that utilized catheterization for bladder management and had a diagnosis of myelomeningocele or lipomyelomeningocele were included. At this institution, patients were not routinely started on CIC at birth; the decision to initiate CIC was made in collaboration with the Urology service based on medical need (clinical or radiologic indicators of a hostile bladder) or patient desire for continence. A standard SB Clinic Questionnaire form was completed by the patient and/or caregiver upon arrival to the multi-disciplinary SB clinic, which provided data regarding independence in self-catheterization, dressing, bathing, and skin checks (Fig. 1). This information was 
Table 1

Comparison between individual who were caregiver catheterized versus those who performed self-catheterization

\begin{tabular}{|c|c|c|c|c|c|c|}
\hline \multirow[t]{2}{*}{ Variable } & & \multicolumn{2}{|c|}{ Caregiver catheterized } & \multicolumn{2}{|c|}{ Self-catheterized } & \multirow[t]{2}{*}{$p$} \\
\hline & & Total $\mathrm{N}$ & $\mathrm{N}(\%)$ & Total N & $\mathrm{N}(\%)$ & \\
\hline \multirow[t]{2}{*}{ Diagnosis } & Myelomeningocele & 88 & $83(94)$ & 111 & $102(92)$ & 0.59 \\
\hline & Lipomyelomeningocele & & $5(5.7)$ & & $9(8.1)$ & \\
\hline \multirow[t]{3}{*}{ Ethnicity } & Unable to obtain & 89 & $0(0)$ & 111 & $2(1.8)$ & 0.69 \\
\hline & Hispanic & & $58(65)$ & & $71(64)$ & \\
\hline & Non-Hispanic & & $31(35)$ & & $38(34)$ & \\
\hline \multirow[t]{5}{*}{ Race } & Unable to obtain & 89 & $0(0)$ & 111 & $1(0.9)$ & 0.72 \\
\hline & White & & $81(91)$ & & $98(88)$ & \\
\hline & Black & & $6(6.7)$ & & $11(9.9)$ & \\
\hline & Asian & & $1(1.1)$ & & $1(0.9)$ & \\
\hline & American Indian/Alaskan Native & & $1(1.1)$ & & $0(0)$ & \\
\hline Gender & Male & 89 & $37(42)$ & 111 & $62(56)$ & $0.047^{*}$ \\
\hline \multirow[t]{5}{*}{ Functional level } & Thoracic & 89 & $22(25)$ & 111 & $14(13)$ & 0.17 \\
\hline & High lumbar & & $4(4.5)$ & & $10(9)$ & \\
\hline & Mid lumbar & & $32(36)$ & & $41(37)$ & \\
\hline & Low lumbar & & $9(10)$ & & $17(15)$ & \\
\hline & Sacral & & $22(25)$ & & $29(26)$ & \\
\hline Shunt & Yes & 89 & $73(82)$ & 111 & $82(74)$ & 0.18 \\
\hline Independent dressing & Yes & 69 & $27(39)$ & 110 & $92(84)$ & $<0.0001^{*}$ \\
\hline Independent bathing & Yes & 69 & $24(35)$ & 110 & $85(77)$ & $<0.0001^{*}$ \\
\hline \multirow[t]{4}{*}{ Skin checks } & Blank & 70 & $13(19)$ & 110 & $19(17)$ & $<0.0001^{*}$ \\
\hline & Self & & $2(2.9)$ & & $39(35)$ & \\
\hline & Caregiver & & $55(79)$ & & $40(36)$ & \\
\hline & Self and caregiver $=$ both & & $0(0)$ & & $12(11)$ & \\
\hline Intellectual disability & Yes & 68 & $27(40)$ & 101 & $15(15)$ & $0.0005^{*}$ \\
\hline
\end{tabular}

The Fischer's exact test used for calculation of statistical significance. ${ }^{*}$ Statistically significant, $p<0.05$.

then discussed by a Developmental Pediatrician with the patient and caregiver to ascertain the age at which ISC was performed mostly by the patient. Independence in dressing, bathing, and skin checks was also elucidated during this appointment to specify that independence meant that no caregiver was needed to complete these activities. The functional level of the spinal lesion was determined by direct neurological examination at each clinic visit. Cognitive ability was assessed based on available results of neuropsychological testing, through review of school-based individualized educational program (IEP) classifications, or from clinical neurodevelopmental assessments performed by one of the SB clinic Developmental Pediatricians. Cognitive ability and independence in dressing, bathing, and skin checks were only assessed on patients $\geqslant 5$ years of age at the time of the visit. Fine-motor ability was evaluated using the Beery-Buktenica Developmental Test of Visual-Motor Integration-Sixth Edition (Beery VMI) performed as part of a neuropsychology evaluation or a neurodevelopmental assessment performed by one of the Developmental Pediatricians. Patients who learned ISC prior to the creation of a surgically created channel (e.g. Mitrofanoff, Monti) were classified in the urethral ISC group for analysis of age of independence. Written informed consent were obtained from all par- ticipants and/or caregivers. The study was approved by the Institutional Review Board of Baylor College of Medicine.

\subsection{Data analysis}

The Fischer's exact test of equal proportions was used to compare the categorical variables between patients who performed ISC and those who did not; it was also used to compare the categorical variables between those patients who used a surgically created channel versus urethra to self-catheterize. To determine if each functional level of lesion was significantly associated with ISC, each level was compared with the other functional levels as a group. The Mann-Whitney U test was used to compare the age of ISC via a surgically created channel versus via the urethra and to compare the fine motor evaluation scores between groups. For all statistical analyses, $p \leqslant 0.05$ was considered statistically significant.

\section{Results}

Of the 200 individuals in the study, $92.5 \%$ had a diagnosis of myelomeningocele and $7.5 \%$ had a diagno- 
Table 2

Difference in age of independence in self-management of catheterization via urethra versus surgically created channel

\begin{tabular}{|c|c|c|c|c|c|c|c|}
\hline \multirow[t]{2}{*}{ Variable } & \multicolumn{3}{|c|}{ Urethral } & \multicolumn{3}{|c|}{ Surgically created channel } & \multirow[t]{2}{*}{$p$} \\
\hline & $\mathrm{N}$ & Mean \pm SD & 0/50/100 Percentile & $\mathrm{N}$ & Mean \pm SD & 0/50/100 Percentile & \\
\hline Age in years & 75 & $9.37 \pm 3.17$ & $2 / 9 / 17$ & 21 & $9.76 \pm 2.21$ & $7 / 9 / 15$ & 0.72 \\
\hline
\end{tabular}

The Mann Whitney U test showed there was no significant difference in age.

Table 3

Comparison between individual who self-catheterized via urethra versus those who used a surgically created channel

\begin{tabular}{|c|c|c|c|c|c|c|}
\hline \multirow[t]{2}{*}{ Variable } & & \multicolumn{2}{|c|}{ Urethral } & \multicolumn{2}{|c|}{ Surgically created channel } & \multirow[t]{2}{*}{$p$} \\
\hline & & Total $\mathrm{N}$ & $\mathrm{N}(\%)$ & Total N & $\mathrm{N}(\%)$ & \\
\hline \multirow[t]{2}{*}{ Diagnosis } & Myelomeningocele & 85 & $77(91)$ & 25 & $24(96)$ & 0.68 \\
\hline & Lipomyelomeningocele & & $8(9.4)$ & & $1(4)$ & \\
\hline \multirow[t]{3}{*}{ Ethnicity } & Unable to obtain & 85 & $2(2.4)$ & 25 & (0) & $0.03^{*}$ \\
\hline & Hispanic & & $59(69)$ & & $11(44)$ & \\
\hline & Non-Hispanic & & $24(28)$ & & $14(56)$ & \\
\hline \multirow[t]{4}{*}{ Race } & Unable to obtain & 85 & $1(1.2)$ & 25 & $0(0)$ & 0.28 \\
\hline & White & & $77(91)$ & & $20(80)$ & \\
\hline & Black & & $6(7.1)$ & & $5(20)$ & \\
\hline & Asian & & $1(1.2)$ & & $0(0)$ & \\
\hline Gender & Male & 85 & $52(61)$ & 25 & $9(36)$ & $0.039^{*}$ \\
\hline \multirow[t]{5}{*}{ Functional level } & Thoracic & 85 & $11(13)$ & 25 & $3(12)$ & 0.47 \\
\hline & High lumbar & & $6(7.1)$ & & $4(16)$ & \\
\hline & Mid lumbar & & $30(35)$ & & $11(44)$ & \\
\hline & Low lumbar & & $13(15)$ & & $3(12)$ & \\
\hline & Sacral & & $25(29)$ & & $4(16)$ & \\
\hline Shunt & Yes & 85 & $62(73)$ & 25 & $19(76)$ & 1 \\
\hline Independent dressing & Yes & 84 & $73(87)$ & 25 & $18(72)$ & 0.121 \\
\hline Independent bathing & Yes & 84 & $67(80)$ & 25 & $17(68)$ & 0.28 \\
\hline \multirow[t]{4}{*}{ Skin checks } & Blank & 84 & $18(21)$ & 25 & $1(4)$ & 0.22 \\
\hline & Self & & $29(35)$ & & $10(40)$ & \\
\hline & Caregiver & & $28(33)$ & & $11(44)$ & \\
\hline & Self and caregiver $=$ both & & $9(11)$ & & $3(12)$ & \\
\hline Intellectual disability & Yes & 76 & $9(12)$ & 24 & $5(21)$ & 0.31 \\
\hline
\end{tabular}

The Fischer's exact test used for calculation of statistical significance. ${ }^{*}$ Statistically significant, $p<0.05$.

sis of lipomyelomeningocele. The age range at the time of the study visit was 3 to 19 years. One hundred and eleven patients $(55.5 \%)$ reported that they performed ISC for bladder management.

\subsection{Self-catheterization versus caregiver catheterization}

Of the 111 patients who were able to perform their own catheterizations, $92 \%$ had a diagnosis of myelomeningocele, $56 \%$ were male, and $64 \%$ were Hispanic. Male gender was associated with a higher rate of ISC ( $p=0.047)$. Having a thoracic level of lesion, compared to all other levels of lesion, was associated with a lower rate of ISC ( $p=0.041)$. There was no significant statistical difference in the rate of shunted hydrocephalus between the patients who performed ISC and those who did not. Furthermore, there were no statistically significant differences between these groups based on ethnicity, race, lesion level, or diagnosis (Table 1). Among the patients who were $\geqslant$ 5 years of age, there was a difference in the presence of intellectual disability between these two groups. Intellectual disability, in the mild and moderate range, was present in $15 \%$ of the individuals who were able to perform ISC and in $40 \%$ of the patients who were not able to perform ISC ( $p=0.0005)$. Additionally, there was a significant difference in independence in dressing, bathing, and performing skin checks between the groups $(p<0.0001)$. There was no difference between the mean fine motor scores (Beery VMI) in the 51 participants $(46 \%)$ who had this assessment, with mean VMI standard scores of $80.2 \pm 15.3$ for those who performed ISC and $79.1 \pm 15.8$ for those who were not independent in catheterization $(p=0.84)$.

\subsection{Age of self-management}

The mean age of establishing independence in catheterization (reported in 96 [86.5\%] of the patients) was 9.45 years $(\mathrm{SD}=2.97$ years). The range of ISC 
was between 2 to 17 years of age. Children with known intellectual disability learned ISC at an average age of 12.3 years ( $\mathrm{SD}=2.96$ years). When these children were omitted from analysis, the average age for ISC initiation was 9.26 years ( $S D=2.95$ years). There were seven patients $(7.3 \%)$ who learned ISC at $\leqslant 5$ years of age; all of these had a diagnosis of myelomeningocele, five were male, and four had a shunt for hydrocephalus. The difference in the age to ISC between patients who used a surgically created channel versus urethral catheterization was not significant (Table 2).

\subsection{Surgically created channel versus urethral catheterization}

A surgically created channel was used by $22.7 \%$ of patients for ISC. Non-Hispanic ethnicity and female gender were significantly associated with having/using a surgically created channel to be independent with bladder management $(p=0.03$ and 0.039 respectively). There were no statistically significant differences between the individuals who performed ISC via surgically created channel versus urethral catheterization based on race, level of lesion, diagnosis, or shunt status (Table 3). There were no differences in fine motor abilities or in independence in bathing, dressing, or performing skin checks between the individuals who catheterized via a surgically created channel versus those who performed urethral catheterization.

\section{Discussion}

These findings suggest that a higher level of lesion and female gender are associated with a lower rate of ISC in children/adolescents with SB. In the absence of a surgically created channel, it would be understood that the ease of access to catheterizing the urethra would explain the observed difference in gender. Moreover, though few studies have looked at the relationship between level of lesion or shunted hydrocephalus and ISC [15], this study lends credence to the notion that patients with lower level lesions are more likely to utilize ISC than patients with thoracic lesions. However, these results do not support the assertion that patients with shunted hydrocephalus are less likely to be able to perform ISC than those without a shunt [16], as no significant statistical difference in the rate of shunted hydrocephalus was found between patients who did and did not perform ISC.
Among those who catheterized via a surgically created channel, female gender and Non-Hispanic ethnicity are associated with increased self-management. This finding is consistent with Faleiros et al. who reported that among a cohort of 92 Brazilian and German patients, cultural factors influenced the performance of ISC $[16,17]$. In this US cohort, Hispanic ethnicity was associated with a lower incidence of surgically created channel use, which may reflect a cultural preference for a non-invasive approach or a disparity in access to surgical care. As Hispanics are the greatest population in need of myelomeningocele surgical repair in the US and concurrently have a higher urinary incontinence rate and lower satisfaction with bladder management $[18,19]$, these findings are relevant to the management of this growing population within our nation. Overall, the average age of ISC emerges as a target for culturally-appropriate educational interventions to stimulate earlier self-management. To our knowledge, this is the largest US cohort of children in whom factors associated with ISC have ever been studied.

Although methods of teaching ISC have been described $[8,13,20,21]$, no large studies have examined the appropriate age of commencing such education. Campbell et al. reported that 45 Canadian children learned to perform ISC at a mean age of 8 years (range 4.7-15.3 years) [22]. In this US cohort, the mean age to ISC was 9.45 years $(\mathrm{SD}=2.97$ years; range 2 to 17 years) and in those individuals with known intellectual disability, it was 12.2 years $(\mathrm{SD}=2.96$ years). This illustrates that while individuals with intellectual disability may lag in initiating ISC, their cognitive ability alone should not preclude them from being taught these skills. Though controversy exists concerning the indications for commencement of clean intermittent catheterization and treatment with anticholinergic medications [23], once underway a case can be made for a proactive approach to ISC. Given the improved longevity of individuals with $\mathrm{SB}$, transitional care issues (such as health-related independence) are becoming progressively more vital. Thus, given the wide age range for initiating ISC, it can be advocated that it is never too early or late to initiate participation in urological self-care skills, and that ISC should commence at the earliest possible age [24].

Determinants of successful ISC teaching programs for children have long been of interest [25]. However, in an era of limited access to comprehensive evaluations and of diminishing reimbursement for such evaluations, there is a need to be able to easily assess a child's readiness to initiate ISC. In this study, while 
both compared groups had expected below average VMI standard scores, there was no difference between those who used ISC and those who did not, suggesting that fine motor abilities are not the major determinant of urologic self-management. Furthermore, cognitive impairment did not preclude ISC, since in the ISC group $15 \%$ had mild to moderate intellectual disability. Most importantly, the findings demonstrate that existent self-efficacy regarding activities of daily living (i.e. dressing, bathing, skin care) are more likely associated with ISC.

Peny-Dahlstrand et al. documented that many children living with SB had difficulties executing activities of daily living in an effortless, efficient and independent way, which at the time was understood to be modulated by both motor and process abilities [26]. Subsequently, the neurostructural association between fine motor dexterity and executive function has been demonstrated [27]. Thus, the assertion that to reach independence in daily life, children with SB need guidance to overcome process deficits, to acquire not only 'how to do things' but also 'how to get things done' is becoming evident [26]. Consequently, as with other activities of daily living, increasing the use of ISC will necessitate intentional parental support and encouragement early in life for children to attain the set of skills required for later autonomy.

The role of an 'independent spirit' within the training and rehabilitation process has long been believed to be important [28]. In this study, a sense of independence was seemingly illustrated in the relationship observed among ISC and independence in dressing, bathing and skin care. Although the impact of parental behaviors on ISC was not addressed in this study, the potential role it may play in the initiation and adherence to ISC cannot be ignored [29]. This observation would be in direct agreement with current literature linking parenting behaviors with medical adherence and autonomy in the SB population, as it has been suggested that higher levels of adaptive parent behaviors (i.e., enforcing developmentally appropriate limits, termed behavioral control) buffers against the negative effect of expected lower levels of executive functioning in children with SB [30,31]. Concurrently, it has been suggested that the level of maladaptive parent behaviors (i.e., intrusive actions that inhibit self-sufficiency development, termed psychological control) is inversely related to levels of medical autonomy and adherence [30-32]. Thus, it has been described that parental behavioral control and psychological control may moderate the relationship between executive functions and medical adherence [31]. As a whole, these studies intrinsically conjoin the role parents have in supporting the early initiation of and constancy with self-management practices.

Lastly, similar to the role of parents, the responsibility of medical providers cannot be ignored. Historically, ISC has been an area of nursing expertise, and physicians have often readily delegated this task. However, in this new era, an inter-professional approach within a multidisciplinary clinic is an ideal environment to support early ISC training through multiple providers. Thus at an early age, providers can discuss parental attitudes and expectations regarding selfcatheterization in order to address barriers to adopting this self-management skill.

\subsection{Limitations}

This clinical study had several limitations. An important limitation was that a standardized instrument, with known reliability and validity, was not used to determine independence.

In addition, there was the lack of a direct evaluation of cognitive ability and fine motor skills among all of the patients, as these are often impaired in the SB population and may affect acquisition and execution of ISC. It is important not to overstate the apparent association found between the ability to perform activities of daily living and ISC; however, given the large sample, there can be confidence that this association is an important observation. Care should also be taken not to overgeneralize the findings to all SB populations, as while this cohort was diverse and a large sample, it only represents one clinic's experience; it would be instructive to look at this issue among a national cohort. Beyond race and ethnicity, parental factors/involvement and their influence on ISC were not investigated; this should be an area of future research. Additionally, since this study only included seven patients who learned ISC at $\leqslant 5$ years of age, it would be of great value to identify how those children who learned ISC at this young age differed from those who learned later. Lastly, there is recognition that future studies are warranted to better clarify the extent of the impact on quality of life that ISC has on individuals with SB and their families.

\section{Conclusions}

These findings suggest that a higher level of lesion and female gender are associated with a lower rate of 
ISC in children/adolescents with SB. In this study, the mean age to ISC was 9.45 years $(\mathrm{SD}=2.97$ years), and thus, the average age of ISC emerges as a target for culturally-appropriate educational interventions to encourage early independence. While the mastery of activities of daily living was not conclusively proven to be a predictor for readiness to participate in ISC, our study does set the stage for future research on factors that may foster an 'independent spirit' early in childhood. Encouraging self-care is an opportunity to provide early guidance in the journey to self-management and transition to adulthood.

\section{Acknowledgments}

The authors thank Dr. Robert Voigt for his thoughtful review of the manuscript and especially each of the families who participated.

\section{Conflict of interest}

The authors have no conflict of interest to report.

\section{References}

[1] Lloyd JC, Wiener JS, Gargollo PC, Inman BA, Ross SS, Routh JC. Contemporary epidemiological trends in complex congenital genitourinary anomalies. The Journal of Urology. 2013 Oct; 190(4 Suppl): 1590-5.

[2] Ouyang L, Grosse SD, Armour BS, Waitzman NJ. Health care expenditures of children and adults with spina bifida in a privately insured US. population. Birth Defects Research Part A, Clinical and Molecular Teratology. 2007 Jul; 79(7): 552-8.

[3] Szymanski KM, Misseri R, Whittam B, Kaefer M, Rink RC, Cain MP. Quantity, Not Frequency, Predicts Bother with Urinary Incontinence and its Impact on Quality of Life in Adults with Spina Bifida. The Journal of Urology. 2016 Apr; 195(4 Pt 2): 1263-9.

[4] Lapides J, Diokno AC, Silber SJ, Lowe BS. Clean, intermittent self-catheterization in the treatment of urinary tract disease. The Journal of Urology. 1972 Mar; 107(3): 458-61.

[5] Wyndaele JJ, Brauner A, Geerlings SE, Bela K, Peter T, Bjerklund-Johanson TE. Clean intermittent catheterization and urinary tract infection: review and guide for future research. BJU International. 2012 Dec; 110(11 Pt C): E910-7.

[6] Pinder B, Lloyd AJ, Elwick H, Denys P, Marley J, Bonniaud V. Development and psychometric validation of the intermittent self-catheterization questionnaire. Clinical Therapeutics. 2012 Dec; 34(12): 2302-13.

[7] Newman DK, Willson MM. Review of intermittent catheterization and current best practices. Urologic Nursing. 2011 JanFeb; 31(1): 12-28, 48; quiz 29.
[8] Cobussen-Boekhorst HJ, Kuppenveld Van JH, Verheij PP, Jong De LL, Gier De RR, Kortmann BB, et al. Teaching children clean intermittent self-catheterization (CISC) in a group setting. Journal of Pediatric Urology. 2010 Jun; 6(3): 288-93.

[9] Amarenco G, Guinet A, Jousse M, Verollet D, Ismael SS. Pencil and paper test: a new tool to predict the ability of neurological patients to practice clean intermittent self-catheterization. The Journal of Urology. 2011 Feb; 185(2): 578-82.

[10] Parsons BA, Narshi A, Drake MJ. Success rates for learning intermittent self-catheterisation according to age and gender. International Urology and Nephrology. 2012 Aug; 44(4): 1127-31.

[11] Hunt GM, Whitaker RH, Doyle PT. Intermittent self catheterisation in adults. British Medical Journal. 1984 Aug 25; 289(6443): 467-8.

[12] Shaw C, Logan K, Webber I, Broome L, Samuel S. Effect of clean intermittent self-catheterization on quality of life: a qualitative study. Journal of Advanced Nursing. 2008 Mar; 61(6): 641-50.

[13] Hannigan KF. Teaching intermittent self-catheterization to young children with myelodysplasia. Developmental Medicine and Child Neurology. 1979 Jun; 21(3): 365-8.

[14] Neef NA, Parrish JM, Hannigan KF, Page TJ, Iwata BA. Teaching self-catheterization skills to children with neurogenic bladder complications. Journal of Applied Behavior Analysis. 1989 Fall; 22(3): 237-43.

[15] Steinhart S, Kornitzer E, Baron AB, Wever C, Shoshan L, Katz-Leurer M. Independence in self-care activities in children with myelomeningocele: exploring factors based on the International Classification of Function model. Disability and Rehabilitation. 2016 Nov; 10: 1-7.

[16] Faleiros F, Kappler C, Costa JN, Favoretto N, Pontes F. Predictive Factors for Intermittent Self-catheterization in German and Brazilian Individuals With Spina Bifida and Neurogenic Bladder Dysfunction. Journal of Wound, Ostomy, and Continence Nursing: Official Publication of The Wound, Ostomy and Continence Nurses Society. 2016 Nov/Dec; 43(6): 63640 .

[17] Costa JN, Silva G, Carvalho Z, Almeira P. Factors that influence the procedure of clean intermittent catheterization in children with myelomeningocele. Rev Enferm UFPE On Line. 2009; 3(4): 864-74.

[18] Kshettry VR, Kelly ML, Rosenbaum BP, Seicean A, Hwang L, Weil RJ. Myelomeningocele: surgical trends and predictors of outcome in the United States, 1988-2010. Journal of Neurosurgery Pediatrics. 2014 Jun; 13(6): 666-78.

[19] Chowanadisai M, de la Rosa Perez DL, Weitzenkamp DA, Wilcox DT, Clayton GH, Wilson PE. The role of ethnicity and culture on functional status in children with spina bifida. Journal of Pediatric Rehabilitation Medicine. 2013 Jan 01; 6(4): 205-13.

[20] Le Danseur M, Stutzman SE, Wilson J, Sislak I, Olson DM. Is the CABIC Clean Intermittent Catheterization Patient Education Effective? Rehabilitation Nursing: The Official Journal of the Association of Rehabilitation Nurses. 2016 Oct 24.

[21] Holland JE, DeMaso DR, Rosoklija I, Johnson KL, Manning D, Bellows AL, et al. Self-cathing experience journal: Enhancing the patient and family experience in clean intermittent catheterization. Journal of Pediatric Urology. 2015 Aug; 11(4): 187 e1-6.

[22] Campbell JB, Moore KN, Voaklander DC, Mix LW. Complications associated with clean intermittent catheterization in children with spina bifida. The Journal of Urology. 2004 Jun; 171(6 Pt 1): 2420-2. 
[23] Snow-Lisy DC, Yerkes EB, Cheng EY. Update on Urological Management of Spina Bifida from Prenatal Diagnosis to Adulthood. The Journal of Urology. 2015 Aug; 194(2): 28896.

[24] Gribble N, Parsons R, Donlau M, Falkmer T. Predictors of time to complete toileting for children with spina bifida. Australian Occupational Therapy Journal. 2013 Oct; 60(5): 3439.

[25] Segal ES, Deatrick JA, Hagelgans NA. The determinants of successful self-catheterization programs in children with myelomeningoceles. Journal of Pediatric Nursing. 1995 Apr; 10(2): 82-8.

[26] Peny-Dahlstrand M, Ahlander AC, Krumlinde-Sundholm L, Gosman-Hedstrom G. Quality of performance of everyday activities in children with spina bifida: a population-based study. Acta Paediatrica. 2009 Oct; 98(10): 1674-9.

[27] Ware AL, Kulesz PA, Williams VJ, Juranek J, Cirino PT, Fletcher JM. Gray matter integrity within regions of the dorsolateral prefrontal cortical-subcortical network predicts executive function and fine motor dexterity in spina bifida. Neuropsychology. 2016 May; 30(4): 492-501.
[28] Karr W. The independent spirit as part of the rehabilitation process. Rehabilitation Literature. 1983 May-Jun; 44(5-6): 153-5.

[29] Clarkson JD. Self-catheterization training of a child with myelomeningocele (toileting independence, incontinent children). The American Journal of Occupational Therapy: Official Publication of the American Occupational Therapy Association. 1982 Feb; 36(2): 95-8.

[30] Steinber L. Autonomy, conflict, and harmony in the family relationship. In: Feldman SS, Elliott GR, eds. At the Threshold: The Developing Adolescent. Cambridge, MA: Harvard University Press; 1990; p. 255-76.

[31] O'Hara LK, Holmbeck GN. Executive functions and parenting behaviors in association with medical adherence and autonomy among youth with spina bifida. Journal of Pediatric Psychology. 2013 Jul; 38(6): 675-87.

[32] Barber BK, Harmon EL. Violating the self: Parental psychological control of children and adolescents. In: Barberr BK, ed. Intrusive Parenting: How Psychological Control Affects Children and Adolescents. Washington DC: American Psychological Association; 2001; p. 15-52. 